\title{
Electronic data safes as an infrastructure for transformational government? A case study
}

Pfister, Joachim ; Schwabe, Gerhard

\begin{abstract}
This article introduces and explores the potential of an active electronic data safe (AEDS) serving as an infrastructure to achieve transformational government. An AEDS connects individuals and organizations from the private and the public sector to exchange information items related to business processes following the usermanaged access paradigm. To realize the transformational government's vision of user-centricity, fundamental changes in the service provision and collaboration of public and private sector organizations are needed. Findings of a user study with a prototype of an AEDS are used to identify four barriers for the adoption of an AEDS in the light of transformational government: (1.) offering citizens unfamiliar services having the character of experience-goods; (2.) failing to fulfill common service expectations of the customers; (3.) failing to establish contextual integrity for data sharing, and, (4.) failing to establish and run an AEDS as a multi-sided platform providing an attractive business model.
\end{abstract}

DOI: https://doi.org/10.1007/978-3-319-22479-4_19

Posted at the Zurich Open Repository and Archive, University of Zurich

ZORA URL: https://doi.org/10.5167/uzh-122359

Conference or Workshop Item

Accepted Version

Originally published at:

Pfister, Joachim; Schwabe, Gerhard (2015). Electronic data safes as an infrastructure for transformational government? A case study. In: EGOV ePart 2015, Thessaloniki, Greece, 30 August 2015 - 3 September 2015. Springer, 246-257.

DOI: https://doi.org/10.1007/978-3-319-22479-4_19 


\title{
Electronic Data Safes as an Infrastructure for Transformational Government? A Case Study
}

\author{
Joachim Pfister, Gerhard Schwabe \\ University of Zurich, Department of Informatics, Zurich, Switzerland \\ \{pfister, schwabe\} @ifi.uzh.ch
}

\begin{abstract}
This article introduces and explores the potential of an active electronic data safe (AEDS) serving as an infrastructure to achieve transformational government. An AEDS connects individuals and organizations from the private and the public sector to exchange information items related to business processes following the user-managed access paradigm. To realize the transformational government's vision of user-centricity, fundamental changes in the service provision and collaboration of public and private sector organizations are needed. Findings of a user study with a prototype of an AEDS are used to identify four barriers for the adoption of an AEDS in the light of transformational government: (1.) offering citizens unfamiliar services having the character of experience-goods; (2.) failing to fulfil common service expectations of the customers; (3.) failing to establish contextual integrity for data sharing, and, (4.) failing to establish and run an AEDS as a multi-sided platform providing an attractive business model.
\end{abstract}

Keywords: electronic data safes, transformational government, user-managed access, case study, barriers

\section{Introduction}

In many countries, electronic government (e-government) initiatives have been introduced that are progressing from the stage of information provisioning and simple transactions to more customer-centric stages of integrated service delivery [1]. Several egovernment maturity models and e-government definitions have been proposed [2] but, actually, many e-government initiatives resulted in digitizing existing practices and were not able to reach more mature stages. In recent years, the idea of "transformational government" (t-government) gained momentum which is defined as "[...] the ICTenabled operations, internal and external processes and structures to enable the realization of services that meet public-sector objectives such as efficiency, transparency, accountability and citizen centricity." [3] The realization of t-government entails fundamental changes in the public service sector's practices and structures, for instance organizations need to cooperate and integrate their activities [4]. This means to overcome data silos, take a holistic view on the relationships between the public sector and citizens or private sector stakeholders and to empower the citizens [5]. This results in a more efficient service delivery and a more transparent and responsive government [1].

adfa, p. 1, 2015.

(c) Springer-Verlag Berlin Heidelberg 2015 
In this paper, the concept of active electronic data safes (AEDS) as an infrastructure to support t-government is introduced and will be explored empirically. These AEDS are based on the paradigm of user-managed access, i.e. that an individual decides which information items are shared with an organization. Using the genre of a case study, a prototypical implementation of an AEDS connecting citizens, the public administration and private sector companies will be analyzed. This concept of user-managed access put into practice will be used to identify challenges with respect to t-government. Therefore, the research questions is: What are the challenges with respect to t-government when the concept of user-managed access with an AEDS is put into practice?

The contribution of this article is to identify challenges for solutions supporting tgovernment that follow the paradigm of user-managed access based on a user study with ordinary citizens. Such an approach helps to complement existing literature-based approaches. For electronic data safes, to the best of our knowledge, no evaluation exists helping to identify this new class of tool's implementation challenges. Heath et al. [6] describe evaluation results from an AEDS-like tool but not with a focus on user perceptions. And research concerning the adoption of an electronic postal service, which also goes into the direction of an AEDS, has been carried out by Berger and Hertzum [7], but they are focusing more on the challenges of the organizational introduction.

Existing research on the adoption of t-government and the identification of potential barriers to t-government is performed on a very high level such as analyzing the policies of national governments to assess their t-government readiness [27]. Other research contributions use case studies in which they interview experts that are responsible for designing and running e-government services [1, 4]. Moreover, technological solutions that support t-government's service delivery are also researched: For example a platform-based approach $[16,28]$ to exchange data is discussed but only from a G2B perspective and with a focus on platform governance and information infrastructure. Hence, in existing research with respect to t-government, the individual as a citizen is rather put aside although user-centricity is a widely heralded tenet of t-government. We argue that a thorough understanding of the socio-technological issues is needed before services are designed. A deeper understanding of the citizens' needs and preferences contributes to successful service design which will entail adoption by the citizens. This point of view has been recognized in IS research [29] and needs to be embraced in the t-government context, too. To achieve this, early testing and gaining feedback from potential end-users of t-government services is needed to uncover yet unknown barriers that may surmount existing categories such as organizational and managerial or technical. This is done in exploratory research that will navigate through the problem domain, discover unknown phenomena and suggest hypotheses or propositions - an approach we have chosen to follow in this article.

Therefore, this article closes the gap of having a lack of understanding in the context of t-government what potential end users think of tools following the user-managed access paradigm. T-Government practitioners and policy makers can use the newly identified challenges to address them in the service design of solutions, for example an AEDS, that are needed to realize the vision of t-government. 


\section{Background}

This section provides background information on the concept of an AEDS. We suggest that an AEDS can serve as an infrastructure component to support t-government. Existing barriers identified in the literature to achieve t-government will be presented, too.

\subsection{Active Electronic Data Safes}

In the domain of e-government, electronic data safes have been proposed as a cloudbased service to securely store documents and data $[8,9]$. These services are evolving from portals [10] and plain document storage solutions to an infrastructure component for user-managed information and process management [11, 12]. The user-managed access paradigm is the central design principle of an electronic data safe which means that the safe owners decide with whom and with which e-business or e-government processes they share their information items. This article uses the term "active electronic data safe" in order to emphasize the process support capabilities that transcend mailbox-like document reception and storage. Thus, an AEDS serves as an "one-stopshop" [13, 14], i.e. an individual's single contact and interaction point for information items and processes related to organizations from the public and the private sector.

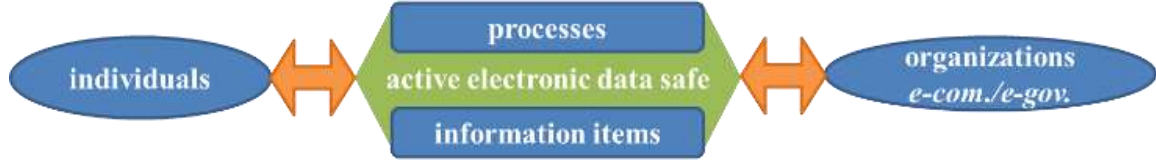

Fig. 1. Active electronic data safe as an intermediary.

Active electronic data safes act as an intermediary replacing many point-to-pointconnections and they serve as a multi-sided platform (MSP) to connect individuals and organizations - both, from the private and the public sector [15] (see Figure 1). Connecting the public and private context via a MSP in the e-government context was diagnosed as an embryonic research area [16]. The simultaneous use of an infrastructure component, such as an AEDS, by the private and public sector makes sense because one organization alone often has too few customer contacts in order to justify the development and maintenance of such an infrastructure. For example, a German citizen is said to have one to two contacts with the public administration per year [17]. AEDS are a network good: The more organizations offer services on an AEDS' platform, the more attractive it will become for customers - and vice versa. Postal services or telecommunication providers who consider themselves as established and natural intermediaries are complementing their portfolio of electronic document delivery solutions, for example, by providing electronic payment, authentication or secure storage for individuals and organizations [18], thus, also moving into the direction of AEDS. Nevertheless, these classic intermediaries often stick to a document-centric "mailbox" metaphor which is extended in the AEDS' vision by process support capabilities or value-added services to assist in personal information management [12] tasks. 


\subsection{AEDS as an Infrastructure for T-Government}

With an AEDS, individuals benefit from a reduction in information fragmentation [19], something that happens, for example, when electronic bills are distributed over several provider-specific online portals. Now, customers are equipped with a tool for exerting informational self-determination in the sense of "vendor relationship management" [20] which is an inverse of the provider-centric idea of customer relationship management (CRM). An AEDS as an intermediary (a) reduces transaction costs and increases the entire transaction value for all participants [21] and (b) overcomes the problems of information silos [22]. Using an AEDS, service provider-specific information silos are replaced by a collaboration of autonomous organizations forming a value chain network [1] glued together by the individual's decision for sharing. This also supports t-government's aims of citizen empowerment: With an AEDS, individuals have the power to decide with whom they will share information items while, at the same time, they still will have an overview which organizations stores what about them. Moreover, this will also contribute to realize the t-government's aims to benefit from fully (horizontally and vertically) integrated government services and citizens having only one contact point for interacting with the public or private sector. To achieve this, all the stakeholders are required to undergo considerable changes - something that needs to be sparked by the introduction of citizen-centric services [3]. Following this line of argumentation, an AEDS will serve as a tool to surmount "the wall" placed in between a governmentcentric CRM view and the vision of a citizen-centric, co-production oriented, empowered and engaged citizen [cf. 23].

Related work that employs the user-managed access paradigm can be found in the domain of electronic health [24]. Therein, collaboration between different stakeholders (patients, health care providers, insurance companies) is needed but information silos prevail. To overcome this situation, personal health records (PHR) have been suggested. They contain the lifelong medical information of a patient and are maintained and shared by the patients themselves - in analogy to an AEDS. These PHRs can be stored with private sector based intermediaries such as Google Health or Microsoft HealthVault, also supporting the user-managed access paradigm. Research in the ehealth domain [25] has shown that the acceptance of such PHR systems suffers from issues related to privacy, autonomy, and accessibility.

\subsection{Barriers to T-Government}

Veenstra et al. [1] developed a literature-based categorization of impediments to achieve the stage of t-government and added empirically derived impediments on the basis of three case studies which involved interviewing three key people from line management and ICT staff. In total, they identified 23 impediments which were grouped into three main categories: governance (7 impediments), organizational and managerial (9 impediments), and technical (7 impediments). Veenstra et al. could confirm twelve literature-based impediments and identify eleven new ones. On the governance level, the main barriers were identified as a lack of a government-wide strategy and vision enabling collaboration in forms of networks and value chains. On the organizational 
and managerial level, huge and joint efforts of stakeholders embedded in complex relationships are needed which creates many barriers. In addition, on the technological level, the lack of knowledge to achieve innovations, for instance due to an organization's dependency upon legacy systems, has been diagnosed. Moreover, Weerakkodyet al. [26] identified challenges and issues for achieving t-government. They carried out a case study to empirically identify challenges that added to the literature-based ones. Therefore, they interviewed e-government practitioners on their experiences but no citizens. 48 change barriers have been identified which were grouped into four categories (in brackets: number of identified change barriers): organizational challenges (19), process change challenges (11), IS/IT integration challenges (8), and cultural and social challenges (10; such as fear of information technology or organizational resistance).

\section{$3 \quad$ Research Design}

As presented in the previous sections, current research on t-government seems to neglect the individual as a citizen who interacts with t-government services. To overcome this weakness, we will carry out an exploratory user study involving twelve citizens and three representatives of public and private sector organizations which will serve as this case study's empirical foundation. In order to enable an in-depth and hands-on experience with the concept of an AEDS, the user study participants (six male and six female; average age 27.6 years) worked in a lab-based setting with a prototype. The three tasks they worked upon were designed to realistically mirror exceptional, but nevertheless, common business transactions with a sufficient degree of complexity: (a) to report a theft to the Police, (b) to file a claim with an insurance company and (c) to get a quote from a security company based on some fictitious vulnerabilities of the home such as a weak door. Three representatives of organizations (Police, insurance and a security company) were involved to interact with the study participants through the AEDS prototype (answering/asking questions through a messaging component) and to evaluate the usefulness of the exchanged information items that have been captured by the study participants (taking photos of valuables and electronically attaching receipts to build an inventory list). After the tasks have been carried out, all the participants completed a questionnaire with respect to technology acceptance which also contained additional items to ask about the participant's attitude towards a possible future adoption of an AEDS. Finally, a semi-structured interview was carried out and audio recorded. The interviews were transcribed and qualitative content analysis was performed using the method of a thematic analysis [30] which has proven to be successful in the field of HCI [31]. Following the transcription, initial codes were assigned using the software MAXQDA. After iteratively reading and refining the coding, themes were assigned in a "data-driven" manner. Writing internal project reports served to review the emerging themes and to discuss them with fellow researcher before defining, naming and compiling them in a final report. 


\section{Barriers to T-Government in the Context of an AEDS}

Based on the empirical data elaborated in the user study and applying the thematic analysis as a method, four barriers to achieve the stage of t-government using an AEDS were identified. We acknowledge that other factors originating from other components that contribute to t-government might lead to further barriers. However, we argue that due to our research design the identified barriers are related predominately to the AEDS. The participants were primed by the quasi-realistic tasks in the user study that enabled them afterwards to thoroughly reflect upon the experienced and future suitability of the user-managed-access paradigm. Quotations are added in order to illustrate the identified themes based on the interpreted data, an approach that is common in qualitative analysis [30]. They have been translated into English by an author of this article.

\subsection{Offering Unfamiliar Services Having the Character of Experience-Goods}

The results from the user study show that the study participants preferred clearly structured processes like filing a claim with an insurance company. The study participants were asked to rate which future business transactions they would like to carry out with an AEDS (Likert-scale ranging from 1 = no, never; 4 = undecided; 7 = yes, absolutely), which resulted in the following ranking: Obtain a quote from a security company (3.36); Manage personal information items in an AEDS (4.55); Report a theft to the Police (5.00); Inventory important objects or documents (5.00); File a claim with an insurance company (5.45). Citizens and service-providers disliked openly structured or largely unknown business processes which lack prior experience or that require a highly individualized configuration. This has been observable with the task of obtaining a quote from a security company. Looking at the interview data, an explanation for this observation can be given: In such open and unknown business processes, the study participants feared to receive the wrong product or the wrong service. Under such circumstances, participants emphasized the need for having a human providing trust and guidance, something which is not necessary in well-known and already experienced formbased business processes such as filing a claim with an insurance company. "Especially the security company, I would like to have personal contact with. With bureaucratic processes, like in an insurance company, I would more readily accept guidance by a program." (P11) Furthermore, obtaining a quote from a security company can be regarded as a service that needs substantial explanatory support for which not every necessary detail can be transmitted via online channels to achieve satisfying results. Thus, such a kind of service falls into the category of delivering experience goods [32]. It seems unlikely that experience good-like services can be fully supported via intermediaries such as an AEDS; a partial support in less critical transaction phases such as billing might be possible. Because citizens seem to prefer known business process transaction schemes, an AEDS should first provide transactional processes that support self-services which will help to familiarize with an AEDS. Complex services transaction schemes with a higher degree of individualization should be provided later. Summing up, we conclude in barrier 1: Offering unfamiliar services that have a character of experience-goods will be a barrier to an AEDS' adoption. 


\subsection{Failing to Fulfil Common Service Expectations of the Customers}

The participants in the user study complained about having too little information about the current status of a business process they had started because the prototype did not implement such a functionality. The different philosophies for delivering an effective and efficient service can be identified quite prototypically following a traditional private/public sector distinction. "The claimants want something from us [the Police] therefore it is their duty to provide correct information." (Police representative) Private sector organizations, such as an insurance company, aim at customer satisfaction: "Customers should always know about the current status of their case." (insurance company representative) Therefore, providing status updates comes natural to them. In contrast, the Police as a public sector organization neglects providing such established success factors in e-business [33] because yet, they did not need to embrace a customercentric view. This is due to various reasons (resources, strategy etc.). Therefore, we conclude in barrier 2: Not fulfilling common service expectations of the customers will result in a barrier to an AEDS's adoption.

\subsection{Failing to Establish Contextual Integrity for Data Sharing}

In the user study, the participants raised privacy and security concerns. They wanted to know what happens with their shared data: where is it stored and who can access it? Using a cloud-based service, such as an AEDS, for storing personal information items was criticized and rationalized at the same time. Some participants (five out of twelve) felt generally unsafe having stored personal data in the cloud. One participant framed this feeling of insecurity as follows: "I would like to control my documents. I would like to know who has access to it. Nobody can guarantee this if I am using Dropbox or Skydrive. And if it rains, then 'the cloud' has gone. I do not trust them. I use cloud services, but only for insignificant stuff." (P02) If an end-to-end encryption exists, as stated by a tech-savvy participant (P12), he would not have any concerns. The service's geographic location was the decisive factor for another participant: "Probably, I would inform myself before I would use such a service. I would prefer such a service being located in Germany, Switzerland or the European Union." (P08) Thoughts about security influenced their decision what should be stored in an AEDS and what not. The same participant (and three more of twelve) explained his preference for having a public sector organization to run an AEDS instead of a private sector company or a start-up company: "I consider a public authority to be more qualified than a private sector company. With a private company, I feel afraid that they might abuse my data for advertisement or their own purposes because they want to exploit them commercially. That seems less probable with public sector organizations." (P08) We conclude therefore that creating transparency for information storage and use is an essential design principle for information systems following the user-managed access paradigm. To meet this expectations, already established knowledge of privacy enhancing technologies [34] must be combined with the process-oriented transaction support in an AEDS. The participants in the user study had concerns where and by whom a service is provided. This observation can be attributed to an individual's aim for keeping "contextual integrity", 
a concept developed by Nissenbaum [35]. Therein, information items can be shared guided by norms of appropriation and distribution tied to a certain context. The context is formed by the source, destination and the appropriateness of the content. By exerting control and having transparency, people are able to maintain contextual integrity. This point of view also gains momentum in other areas of research, such as HCI [36]. We, therefore, conclude in barrier 3: Failing to establish contextual integrity will cause a barrier to the adoption of an AEDS.

\subsection{Failing to Establish and Run a Multi-Sided Platform}

Taking the customer perspective, the study participants generally recognized the advantages of creating and receiving information items digitally and their re-use in digital business processes. Having everything at one place and being able to forward information items was judged by nearly all (nine out of twelve) participants as something positive and beneficial: "Forwarding things, for instance to the Police or to an insurance company, would not have been possible with my system [Dropbox]." (P09) Another participant stated, that if he had all his digital belongings and documents organized neatly in an AEDS, he would not like to suffer from a vendor lock-in. The information items as well as all the effort to organize them should not be lost when, due to some reason, a change of the AEDS provider is necessary. Looking at the service-providers, a mixed picture arises: In general, the Police representative was critical about the current prototype. Without a deep integration into the Police's back-end systems (which has not been done in the prototype), he concluded that the AEDS prototype only brings advantages to the citizen and not to him. The insurance company representative was convinced by the concept of an AEDS and its prototypical implementation but wondered about the need for critical mass: "If the usage numbers are big enough, such a concept would be beneficial to us. The problem is to motivate a substantial number of our customers to use such a tool to achieve enough usage." (insurance rep.)

To summarize, an AEDS as a multi-sided platform faces challenges to find a suitable business model that satisfies all relevant stakeholder: (a) the AEDS platform provider, (b) the service-providers from the private and public sector that offer services using the AEDS platform, and (c) the customers willing to engage in business transactions and/or store personal information items. Attracting a sufficient number of customers and service-providers, which is vital for a network good, resembles the well know chickenand-egg problem. In an free market, where many AEDS platform providers compete for customers, they need to differentiate by offering "value-added" services going beyond the simple storage of information items [12]. For example, individuals can be supported in their personal information management by breaking down larger information organizing tasks into smaller tasks that can be worked upon using different devices at different locations, for instance, tagging photos and grouping them into galleries. This strategy is called "Selfsourcing" [37]. It could be complemented for specific tasks with the concept of crowd sourcing which served as the original inspiration for the selfsourcing concept. We summarize these challenges in barrier 4: Failing to establish and run an AEDS as a multi-sided platform with an attractive business model will be a barrier for the adoption amongst all stakeholders. 


\section{Discussion}

In order to categorize the four barriers that have been elaborated in the previous section we argue for the creation of a new, "citizen-oriented service design" category. The four newly discovered barriers do neither resemble impediments on the governance, organizational or managerial or technological level as categorized by Veenstra et al. [1]. Nor, they can be understood as "organizational and social" challenges within an organization, a category used by Weerakkody et al. [26]. The character the four impediments share is related to the citizens, their service expectations, needs or fears. Therefore, we suggest to summarize these four barriers under the new category "citizen-oriented service design". Reflecting upon the newly discovered barriers contributes to the design of AEDS and to t-government at the same time which will be discussed in the following.

Electronic data safes have the potential to help citizens in overcoming the problem of information fragmentation. The ability to interact with business processes transforms electronic data safes into active electronic data safes. Certainly, these tools provide more capabilities for information sharing under the user-managed access paradigm than ordinary portals or electronic data safes. Nevertheless, they will face challenges related to the governance, organizational or managerial, technological or social level. But our results also indicate that the service design needs to pay attention to the individuals as users or customers of an AEDS. Using the perspective of a "citizen-oriented service design", we interpret our findings as a call for action to come up with research to identify further barriers that are related to the citizen who makes use of new technologies and services. In doing so, the following question can be answered to shape new services before they are rolled out: With respect to a new service delivery paradigm, such as an AEDS, which character of services do citizens favor under which conditions?

T-government can benefit from integrating the citizen-oriented service design perspective, too, in order to develop solutions that are truly citizen-centric. As our example with an exploratory study of an AEDS has shown, innovations or new technologies to support t-government need to bring utility not only to the organization but also, and foremost, to the citizen as service users. Thus, they need to have a satisfying degree of maturity. Therefore, we conclude that an assessment of t-government readiness from a user-perspective needs to be integrated in the discussion of future barriers. Instead of just looking back on what went wrong after new services and technologies have been launched, t-government research should take an active stance to identify unknown barriers ahead. User studies in a quasi-realistic setting seem promising to achieve this.

\section{$6 \quad$ Limitations}

As a limitation to this study, the participants in the user study do not reflect a representative part of the population, and the number of service providers might seem too limited and narrow to come up with results having a high internal validity and, thus, not being fruitful for generalization. Nevertheless, (single) case studies produce rich observations and propositions can be derived from all observations helping to guide further theory development, for example, by pointing to new research challenges that 
arise and would not have been found otherwise. This argument reflects this article's exploratory approach to identify future challenges and impediments of an emerging class of tools following the user-managed access paradigm, such as an AEDS. Furthermore, the tasks in the user study were purposefully chosen to cover realistic problems and that the participants could work in a nearly realistic setting (mock home-office).

\section{Conclusion}

In this article, we identified four new impediments or challenges related to an AEDS when such a tool is used to support t-government by offering a technical solution to put the paradigm of user-managed access into practice in order to overcome data silos: 1.) offering citizens unfamiliar services having the character of experience-goods; 2 .) failing to fulfil common service expectations of the customers; 3 .) failing to establish contextual integrity for data sharing; 4.) failing to establish and run a multi-sided platform. Without our exploratory approach involving a user study with a prototype, those impediments would have been not identified. Therefore, we argue that t-government projects benefit from early prototyping and evaluation with all relevant stakeholders in order to avoid misconceptions leading to unusable and not accepted solutions. Usercentered design methods and design science research [38] help to uncover "hidden" assumptions or problematic areas which need to be addressed. Applying such methods and paradigms helps to understand better specific contexts but they may also generate transferable knowledge for other contexts or domains. The study participants welcomed the concept of an AEDS helping them in organizing their administrative burdens. This gives confidence that the concept of an AEDS and its user-managed access approach will fall on fertile grounds. Nevertheless, further research is needed to come up with solutions that tackle the newly identified and existing impediments to t-government.

\section{$8 \quad$ References}

1. Veenstra, A.F.V., Klievink, B., Janssen, M.: Barriers and impediments to transformational government: insights from literature and practice. Electronic Government, an International Journal. 8, 226 (2011).

2. Yildiz, M.: E-government research: Reviewing the literature, limitations, and ways forward. Government Information Quarterly. 24, 646-665 (2007).

3. Weerakkody, V., Janssen, M., Dwivedi, Y.K.: Transformational change and business process reengineering (BPR): Lessons from the British and Dutch public sector. Government Information Quarterly. 28, 320-328 (2011).

4. Dhillon, G.S., Weerakkody, V., Dwivedi, Y.K.: Realising transformational stage e-government: a UK local authority perspective. Electronic Government, an International Journal. 5, 162-180 (2008).

5. CS Transform: Citizen Service Transformation: A manifesto for change in the delivery of public services. (2010).

6. Heath, W., Alexander, D., Booth, P.: Digital Enlightenment, Mydex, and Restoring Control over Personal Data to the Individual. In: Hildebrandt, M., O'Hara, K., 
and Waidner, M. (eds.) Digital enlightenment yearbook 2013: the value of personal data. pp. 253-269. IOS Press, Amsterdam (2013).

7. Berger, J.B., Hertzum, M.: Adoption Patterns for the Digital Post System by Danish Municipalities and Citizens. Proceedings of the European Conference on Information Systems (ECIS) 2014. Tel Aviv, Israel (2014).

8. Breitenstrom, C., Brunzel, M., Klessmann, J.: Elektronische Safes für Daten und Dokumente. Fraunhofer Institut für Offene Kommunikationssysteme (FOKUS), Berlin (2008).

9. Schulz, S., Hoffmann, C., Klessmann, J., Penski, A., Warnecke, T.: Dienste auf Basis elektronischer Safes für Daten und Dokumente. Lorenz-von-Stein-Institut, Fraunhofer FOKUS (2010).

10. Lucke, J. von: Portals for the public sector. In: Anttiroiko, A.-V. and Malkia, M. (eds.) Encyclopedia of Digital Government. pp. 1328-1333. IGI Global (2007).

11. Kuppinger, M., Kearns, D.: Life Management Platforms: Control and Privacy for Personal Data. In: Hildebrandt, M., O’Hara, K., and Waidner, M. (eds.) Digital enlightenment yearbook 2013: the value of personal data. pp. 243-252. IOS Press, Amsterdam (2013).

12. Pfister, J., Schwabe, G.: The Landscape of Electronic Data Safes and Their Adoption in E-Government and E-Business. 46th Hawaii International Conference on System Sciences (HICSS). pp. 1963-1972 (2013).

13. Kohlborn, T., Korthaus, A., Peters, C., Fielt, E.: A Comparative Study of Governmental One-Stop Portals for Public Service Delivery: International Journal of Intelligent Information Technologies. 9, 1-19 (2013).

14. Wimmer, M.A.: Integrated service modelling for online one-stop government. Electronic Markets. 12, 149-156 (2002).

15. Brunzel, M.: Intermediäre Geschäftsmodelle an den Schnittstellen zur öffentlichen Verwaltung. In: Brüggemeier, M. and Lenk, K. (eds.) Bürokratieabbau im Verwaltungsvollzug: Better Regulation zwischen Go-Government und No-Government. pp. 125-134. Edition Sigma, Berlin (2011).

16. Bharosa, N., Janssen, M., Klievink, B., Tan, Y.: Developing multi-sided platforms for public-private information sharing: design observations from two case studies. Proceedings of the 14th Annual International Conference on Digital Government Research. pp. 146-155. ACM (2013).

17. Lenz, T.: E-Government und E-Nonprofit. Management von Internetprojekten in Verwaltung und Nonprofit-Organisationen. Schäffer-Poeschel (2001).

18. Finger, M., Bukovc, B., Burhan, M. eds: Postal Services in the Digital Age. IOS Press, Amsterdam (2014).

19. Tungare, M.: Mental Workload at Transitions between Multiple Devices in Personal Information Management, http://pimworkshop.org/2009/papers/tungarepim2009.pdf, (2009).

20. Project VRM: Main Page - Project VRM, http://cyber.law.harvard.edu/projectvrm/Main_Page.

21. King, R.C., Sen, R., D’Aubeterre, F., Sethi, V.: A Trade Value Perspective on Ecommerce Research: An Integration of Transaction Value and Transaction Cost Theories. Int. J. E-Bus. Res. 6, 59-77 (2010). 
22. Bannister, F.: Dismantling the silos: extracting new value from IT investments in public administration. Information Systems Journal. 11, 65-84 (2001).

23. King, S., Cotterill, S.: Transformational Government? The role of information technology in delivering citizen-centric local public services. Local Government Studies. 33, 333-354 (2007).

24. Duennebeil, S., Sunyaev, A., Leimeister, J.M., Krcmar, H.: Strategies for development and adoption of EHR in German ambulatory care. Pervasive Computing Technologies for Healthcare, 2010 4th Int. Conf. pp. 1-8 (2010).

25. Weitzman, E.R., Kaci, L., Mandl, K.D.: Acceptability of a Personally Controlled Health Record in a Community-Based Setting: Implications for Policy and Design. J Med Internet Res. 11, (2009).

26. Weerakkody, V., Dhillon, G., Dwivedi, Y., Currie, W.: Realising transformational stage e-government: challenges, issues and complexities. AMCIS 2008 Proceedings. 181 (2008).

27. Parisopoulos, K., Tambouris, E., Tarabanis, K.: An investigation of national policies on transformational government (t-Gov) in Europe. International Journal of Information Technology and Management. 13, 305-323 (2014).

28. Janssen, M., Estevez, E.: Lean government and platform-based governance - Doing more with less. Government Inf. Quarterly. 30, Supplement 1, S1-S8 (2013).

29. Brenner, W., Karagiannis, D., Kolbe, L., Krüger, J., Leifer, L., Lamberti, H.-J., Leimeister, J.M., Österle, H., Petrie, C., Plattner, H., Schwabe, G., Uebernickel, F., Winter, R., Zarnekow, R.: User, Use \& Utility Research: The Digital User as New Design Perspective in Business and Information Systems Engineering. Business \& Information Systems Engineering. 6, 55-61 (2014).

30. Braun, V., Clarke, V.: Using thematic analysis in psychology. Qualitative Research in Psychology. 3, 77-101 (2006).

31. Fitzgerald, C.A., Flood, P.C., O’Regan, P., Ramamoorthy, N.: Governance structures and innovation in the Irish Software Industry. The Journal of High Technology Management Research. 19, 36-44 (2008).

32. Girard, T., Korgaonkar, P., Silverblatt, R.: Relationship of type of product, shopping orientations, and demographics with preference for shopping on the Internet. Journal of Business and Psychology. 18, 101-120 (2003).

33. Liu, C., Arnett, K.P.: Exploring the factors associated with Web site success in the context of electronic commerce. Information \& Management. 38, 23-33 (2000).

34. Camenisch, J., Fischer-Hübner, S., Rannenberg, K. eds: Privacy and Identity Management for Life. Springer, Berlin, Heidelberg (2011).

35. Nissenbaum, H.F.: Privacy in context : technology, policy, and the integrity of social life. Stanford Law Books, Stanford, Calif. (2010).

36. Barkhuus, L.: The mismeasurement of privacy: using contextual integrity to reconsider privacy in HCI. Proceedings of the SIGCHI Conference on Human Factors in Computing Systems. pp. 367-376. ACM, New York, NY, USA (2012).

37. Teevan, J., Liebling, D.J., Lasecki, W.S.: Selfsourcing personal tasks. Presented at the CHI 2014, Toronto, Ontario, Canada (2014).

38. Hevner, A.R., March, S.T., Park, J., Ram, S.: Design science in information systems research. MIS Quarterly. 75-105 (2004). 